\title{
'|||||||||||||||||||||||||||||||||||||||||||||||||||||||||||||||||||.
}

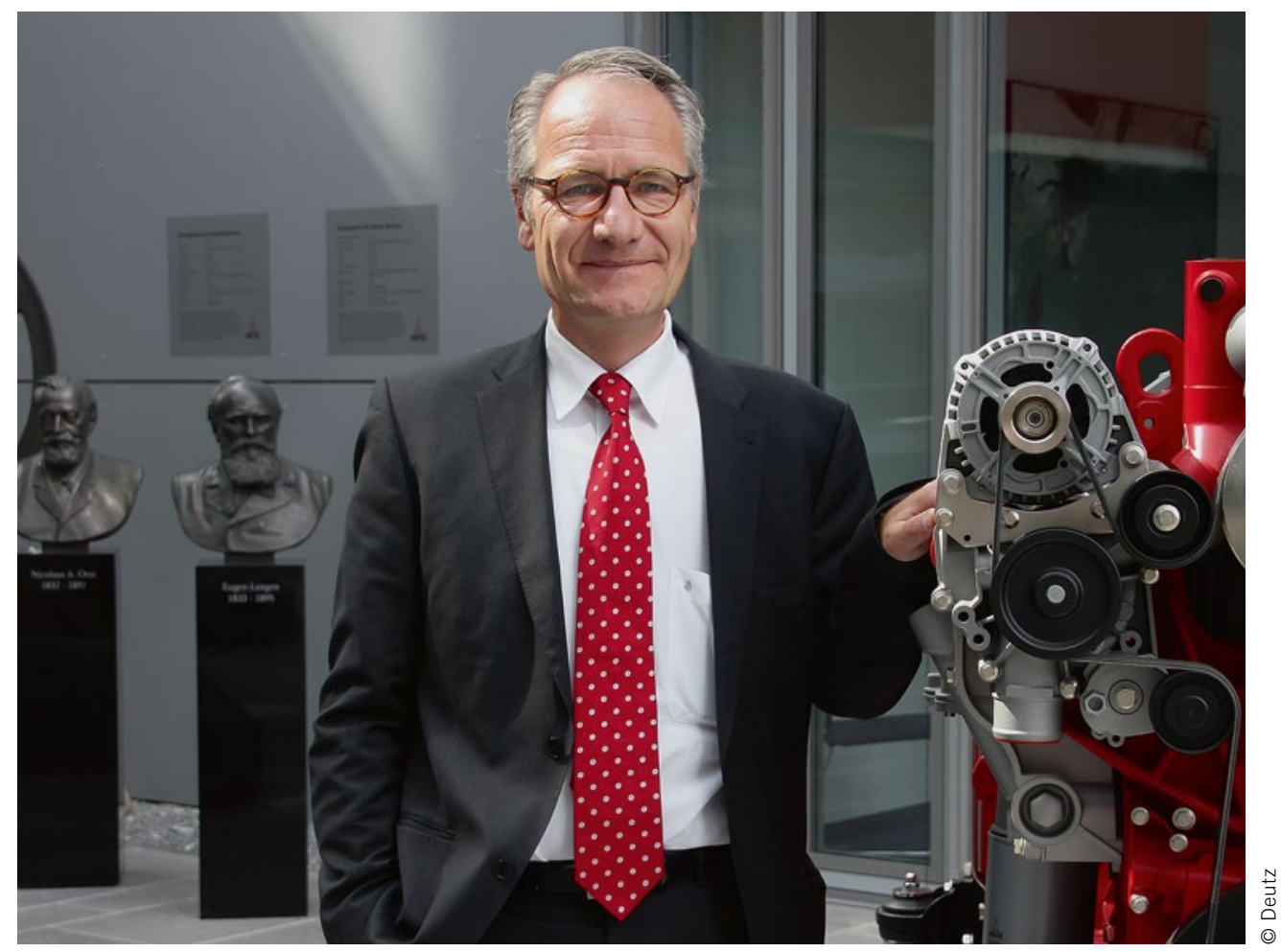

Dr.-Ing. Markus Schwaderlapp Senior Vice President Research \& Development, Deutz AG

\section{Fit for the Future}

Combustion engines are perfect for mobile machines. And this is where they come into their own with their durability, compactness, fuel efficiency, extensive range and, last but not least, a beneficial price/performance ratio. This is true of small engines used in auxiliary units for units conveying oil north of the Arctic Circle as well as high-performance diesel engines in large tractors used by major agricultural enterprises. Emission legislation represents a key challenge to driveline development in the off-highway field and has become increasingly stringent worldwide in recent years. Stage V, set to come into force in Europe in 2019, imposes the most significant constraint - the threshold value for the number of particles requires a closed particulate filter. All Deutz engines, with cubic capacity from 2.9 to 7.81 and equipped with diesel particulate filters, already meet this emission limit and thus constitute a sustainable drive solution for the entire range of mobile work machines. In the process, the control unit software handles exhaust after-treatment across the entire engine map. Package solutions have also been developed that integrate the exhaust after-treatment into the entire vehicle range, from earthmovers to tractors.

In other words, the combustion engine has done its "homework" for the next ten to 15 years. However, electrification can also benefit mobile machines. For example, mild hybrids with $48 \mathrm{~V}$ technology and $15 \mathrm{~kW}$ electrical output can enhance the function of start/stop systems, or hydraulic units within the machine can be replaced with electrical alternatives. Whether or not electrification will proceed to the next stage, as with on-highway use, very much depends on price trends and battery performance. Key among the requirements imposed by off-highway use is the increased durability of the unit and the required range.

Networking (Internet of things) is another interesting area for mobile machines and is being developed intensively for agricultural and construction machinery. The engine, including an exhaust system, also has a powerful software package in which a multitude of key data is generated for the machine. Of course, the engine control unit is also interconnected with the vehicle control unit and using telemetry, the fleet-wide deployment to all vehicles can be optimised. Conversely, having direct access to the data software included in the engine control unit can open up a whole new range of potential for the user.

The combustion engine will remain the dominant force in mobile working machines for the coming decades - with electrification and networking set to boost the functional scope considerably. 